\title{
The Change Quality of Life Patients with Upper Limb Lymphedema after the Breast Carcinoma Surgery
}

M. Cernicky (Miroslav Cernicky)', J. Slobodnikova (Jana Slobodnikova)', K. Kaslikova
(Katarina Kaslikova)1,2

\section{Original Article}

${ }^{1}$ Faculty of Healthcare, Alexander Dubcek University of Trencin, Trencin, SK

${ }^{2}$ St. Elizabeth University of Health and Social Work, Bratislava, Doctoral Student, SK

\section{E-mail address:}

miroslav.cernicky@tnuni.sk

\section{Reprint address:}

Miroslav Cernicky

Alexander Dubcek University of Trencin

Studentska 2

91150 Trencin

SK

Source: Clinical Social Work and Health Intervention

Volume: 9

Issue: 1

Pages: $14-20$

Cited references: 15

\section{Reviewers:}

Stefan Durdik

Oncology Institute of St. Elisabeth, Bratislava, SK

Vladimir Bella

Oncology Institute of St. Elisabeth, Bratislava, SK

\section{Key words:}

Breast Cancer. Lymphedema. Quality of Life. Lymphatic Drainage.

\section{Publisher:}

International Society of Applied Preventive Medicine i-gap

CSWHI 2018; 9(1): 14 - 20; DOI 10.22359/cswhi_9_1_02 @ 2018 Clinical Social Work and Health Intervention

\section{Abstract:}

Introduction: Frequent co-morbidity of breast cancer therapy resides in lymphedema due to insufficient drainage of lymphatic fluid from the adjacent upper limb. In addition to mobility restrictions, it also adversely affects the quality of life of patients. An effective therapeutic tool is 
lymphatic drainage techniques suitably supported by vascular gymnastics and limb bandaging.

Objective: In our study, we examined the effect of lymph drainage techniques on the extent of lymphedema and the subjective perception of patients' quality of life.

Methods and methodology: The subjective perception of the quality of life of patients was verified using a questionnaire in a defined period. Respondents were patients after the treatment of breast cancer followed by lymphedema indicating lymph drainage techniques. A total of 126 respondents were surveyed, 59 had mild lymphedema, 41 had moderate lymphedema, and 17 had lymphedema, 9 were not specified in lymphedema.

Results: Differences in female quality of life are statistically significant affected by the three stages of lymphedema severity before lymphadenopathy. ( $\mathrm{P}<0.001)$, hygiene $(\mathrm{p}<0.001)$, food preparation $(\mathrm{p}<0.001)$; domestic work $(\mathrm{p}<0.001)$; shopping $(\mathrm{p}<0.001)$. A certain trend, albeit statistically at the limit of marginal significance was also apparent in the case of walking $(\mathrm{p}<0.09)$. The rate of improvement was directly proportional to the severity of lymphedema prior to initiation of therapy $(\mathrm{p}<0.001)$.

Conclusion: In our study, we verified the high effectiveness of lymph drainage techniques in lymphedema therapy as well as increasing the subjective perception of patients' quality of life.

\section{Conflict of interests:}

The authors whose names are listed in the title of the article certify that they have NO affiliations with or involvement in any organization or entity with any financial interest (such as honoraria; educational grants; participation in speakers' bureaus; membership, employment, consultancies, or other equity interest), or non-financial interest (such as personal or professional relationships, affiliations, knowledge or beliefs) in the subject matter or materials discussed in this manuscript.

\section{Introduction}

Breast cancer affects nearly $7 \%$ of the female population in Europe, and in the US it accounts for about $30 \%$ of all women's cancer. The occurrence of breast cancer 20 years ago was rare, the incidence increased and increased sharply after 50 years of age, directly related to menopause. (1) In addition, breast cancer continues to remain the most widespread malignancy in women, but at the same time there is a stabilized to moderately declining mortality trend for this disease. Trends in mortality decline of $20-30 \%$ were recorded in screened countries. (2,3) The Slovak Republic, with the standardized incidence of 51.6/100,000 breast cancer (which represents 2,177 cases of disease) in the last statistically closed year 2004, lists the occurrence of diseases in countries with Medium. In that year, breast cancer was the most common malignant tumor in women. Breast cancer accounts for $17.7 \%$ of all malignancies in women. 
Mortality reached 19.9/100,000 women (795 cases) in the given year, with stabilization and slight decrease in standardized mortality values (4) in recent years.

Common lymphedema of the adjacent upper limb is a frequent comorbidity of the disease. This is not the painful outcome of surgery, but it significantly affects the quality of life of patients. Literary sources state that about $30 \%$ of women complain of upper limb lymphedema. In addition, lymphedema may occur several years after an operation. The main cause of this condition is the disruption of lymphatic pathways in the axilla during surgery. Secondary lymphedema has been extruded by the medical public for many years at the edge of interest due to insufficient redesign of diagnostics, especially early stage. Patients on therapy were already suffering from obsolete lymphedema, a difficult to treat stage associated with soft tissue fibrosis of the affected area. Another reason was the inability to influence the developed lymphedema by medical therapy. $(5,6,7)$

We divide the lymphedema according to the degree of change in 4 groups; 1) Latent at this stage is not a clinical manifestation; changes are at the cellular level; patients experience subjective difficulties in terms of burning and limb tension. 2) Reversible - it is soft on the palate; the limbs are not lifted. 3) Perennial - stiff; not limiting after the limb is lifted; fibrotic changes are also present on the limb tissue. 4) Elephantiasis - a huge limb with pronounced skin changes - thickening, wart formation - verrucosis lymphostatica; skin cracking and lymphatic leakage - chyloderma. According to the size of the limb, we divide the lymphedema into 3 groups: 1) light lymphedema - up to $2 \mathrm{~cm}$; 2) moderately hard lymphedema - up to $6 \mathrm{~cm} ; 3$ ) hard lymphedema - over $6 \mathrm{~cm}$. (8)

A comprehensive treatment approach to lymphedema includes massages techniques and movement therapy. Surgical treatment is reserved for lymphosarcoma and for the removal of enormous surplus skin lesions following successful conservative treatment of elephantiasis. Its disadvantage is that it violates the surface lymphatic system and thus worsens the possibilities of further conservative treatment. $(5,6,7)$ Literary sources describe the use of the study of possibility of using hyperbaric oxygen therapy as an additive therapy in the treatment of lymphedema. $(9,10,11)$ Hyperbaric oxygen therapy is a therapeutic approach where the patient is exposed to $100 \%$ oxygen at pressures higher than ambient (1 ATA). This leads to an increased blood oxygen level, which than can penetrate to ischemic areas more deeply than under normobaric conditions. $(12,13,14,15)$ Our investigation was realized as a preliminary study of the project focused on the using of the hyperbaric oxygen therapy as a complementary therapy of selected diseases. Previous reports of hyperbaric oxygen therapy for breast edema led us to consider the use of hyperbaric oxygen therapy for arm lymphedema, but there is a need for further studies which should explore the effects of a greater number of hyperbaric oxygen treatments on lymphedema, with more patients.

\section{Aim}

To verify the efficacy of lymphatic drainage techniques applied in patients after breast cancer therapy in patient's perception of quality of life.

\section{Material and Methodology}

A total of 126 respondents were surveyed, 59 had Light lymphedema, 41 had a Medium lymphedema, and 17 had a Hard Lymphedema, in 9 women the extent of lymphedema was unspecified. The sample was aged 20 to 67 years old. The average age of the women was 46 years. 
In our study, we used a non-standardized questionnaire that contained 12 closed questions and 3 semi-closed questions. From the closed questions was 1 dichotomous and 11 polyatomic. Between the questions was also a filtering question. Using the questionnaire, we investigated how lymphatic drainage impacts on the quality of life of patients experiencing that type of treatment. The return of the questionnaire reached $84 \%$.

The scoring of answers in the questionnaire was in the form of ordinal data with a range of five degrees. Due to the nature of the data for individual variables (i.e., individual questions), we used nonparametric statistical tests. We used Kruskal-Wallis to compare the three subfamilies with varying degrees of lymphedema, the differences between the two pairs were tested by a subsequent Dunn Test.

In the case of pairwise testing (before and after therapy of the same individuals), we used the nonparametric pairwise Wilcoxon Test. To verify the interdependence of variables, we used the nonparametric Spearman Correlation Coefficient. The p-value of the test criterion for the statistical test used was $p<0.05$, the differences between tested variables were considered statistically significant.

\section{Results and Discussion}

Primary results of quality of life testing before lymphatic drainage are shown in Table 1 . It results from the fact that the severity of lymphedema statistically significantly restricts all activities of everyday life, with the exception of walking, which significantly affect the perception of the quality of life of the respondents. The problem of the problems in the observed life activities increased proportionally to the extent of lymphedema.

Consequently, we compared the influence of lymphatic drainage techniques on patients' quality of life. The results are shown in Table 2. For better clarity (although at the expense of mathematical and statistical suitability), the arithmetic mean of the variables monitored is given in the table for information purposes only. Table 2 shows two major findings:

- The application of lymphatic drainage technique statistically significantly reduces the subjective perception of impaired quality of life in patients (mostly $\mathrm{p}<0.001$, Wilcoxon Pair Test). Lower values were found only for walking not related to lymphedema of the upper limb.

- Based on the correlation coefficient, a strong positive relationship can be noted between the degree of lymphedema severity in single patients before and after lymphadenopathy. From this, a very important finding can be drawn that lymphatic drainage techniques have a beneficial effect with high constancy, since the rate of improvement is proportional to baseline lymphedema in individuals. 
Table 1: Problems before lymphatic drainage.

\begin{tabular}{|c|c|c|c|c|c|c|}
\hline The severity of lymphedema & Problems & $\mathbf{n}$ & Median & Minimum & Maximum & $p$ \\
\hline Light & \multirow{3}{*}{$\begin{array}{l}\text { changing } \\
\text { clothes }\end{array}$} & 59 & 2.00 & 1.00 & 5.00 & \multirow{3}{*}{$<0.001$} \\
\hline Medium & & 41 & 3.00 & 1.00 & 5.00 & \\
\hline Hard & & 17 & 4.00 & 3.00 & 5.00 & \\
\hline Light & \multirow{3}{*}{ hygiene } & 59 & 2.00 & 1.00 & 4.00 & \multirow{3}{*}{$<0.001$} \\
\hline Medium & & 41 & 2.00 & 1.00 & 5.00 & \\
\hline Hard & & 17 & 4.00 & 3.00 & 5.00 & \\
\hline Light & \multirow{3}{*}{$\begin{array}{l}\text { food } \\
\text { preparation }\end{array}$} & 59 & 2.00 & 1.00 & 4.00 & \multirow{3}{*}{$<0.001$} \\
\hline Medium & & 41 & 3.00 & 1.00 & 5.00 & \\
\hline Hard & & 17 & 4.00 & 2.00 & 5.00 & \\
\hline Light & \multirow{3}{*}{ housework } & 59 & 3.00 & 1.00 & 5.00 & \multirow{3}{*}{$<0.001$} \\
\hline Medium & & 41 & 3.00 & 1.00 & 5.00 & \\
\hline Hard & & 17 & 4.00 & 3.00 & 5.00 & \\
\hline Light & \multirow{3}{*}{ shopping } & 59 & 2.00 & 1.00 & 4.00 & \multirow{3}{*}{$<0.00$} \\
\hline Medium & & 41 & 3.00 & 1.00 & 5.00 & \\
\hline Hard & & 17 & 4.00 & 2.00 & 5.00 & \\
\hline Light & \multirow{3}{*}{ walking } & 59 & 2.00 & 1.00 & 4.00 & \multirow{3}{*}{$<0.09$} \\
\hline Medium & & 41 & 2.00 & 1.00 & 5.00 & \\
\hline Hard & & 17 & 3.00 & 1.00 & 5.00 & \\
\hline
\end{tabular}

Legend: $\mathrm{n}$ - number of patients, $\mathrm{p}$-value of the Kruskal-Wallis test criterion

Table 2: Testing the effect of lymphatic drainage - light lymphedema.

\begin{tabular}{|c|c|c|c|c|c|}
\hline The severity of lymphedema & Problems & $p$ & $R$ & M1 & M2 \\
\hline Light & \multirow{3}{*}{$\begin{array}{l}\text { changing } \\
\text { clothes }\end{array}$} & $<0.001$ & 0.69 & 2.37 & 1.71 \\
\hline Medium & & 0.002 & 0.63 & 2.66 & 2.20 \\
\hline Hard & & $<0.001$ & 0.81 & 4.18 & 3.00 \\
\hline Light & \multirow{3}{*}{ hygiene } & $<0.001$ & 0.66 & 2.15 & 1.61 \\
\hline Medium & & $<0.001$ & 0.80 & 2.56 & 2.07 \\
\hline Hard & & $<0.001$ & 0.42 & 4.18 & 3.24 \\
\hline Light & \multirow{3}{*}{$\begin{array}{l}\text { food } \\
\text { preparation }\end{array}$} & $<0.001$ & 0.69 & 2.34 & 1.73 \\
\hline Medium & & $<0.001$ & 0.73 & 2.73 & 2.12 \\
\hline Hard & & $<0.001$ & 0.78 & 4.06 & 3.24 \\
\hline Light & \multirow{3}{*}{ housework } & $<0.001$ & 0.69 & 2.83 & 2.00 \\
\hline Medium & & $<0.001$ & 0.77 & 3.12 & 2.39 \\
\hline Hard & & $<0.001$ & 0.65 & 4.35 & 3.53 \\
\hline Light & \multirow{3}{*}{ shopping } & $<0.001$ & 0.59 & 2.32 & 1.68 \\
\hline Medium & & $<0.001$ & 0.87 & 2.83 & 2.17 \\
\hline Hard & & $<0.001$ & 0.51 & 4.00 & 2.71 \\
\hline
\end{tabular}




\begin{tabular}{|l|l|l|l|l|l|}
\hline Light & \multirow{4}{*}{ walking } & $<0.001$ & 0.60 & 1.80 & 1.42 \\
\cline { 5 - 6 } Medium & 0.09 & 0.81 & 2.00 & 1.78 \\
\cline { 5 - 6 } Hard & & 0.03 & 0.90 & 2.59 & 2.12 \\
\hline
\end{tabular}

Legend: $\mathrm{p}$ - value of the Wilcoxon pair non-parametric test result test criterion; $\mathrm{R}$ - Spearmanov nonparametric sequence correlation coefficient; M1 - arithmetic mean of activities before lymph drainage; M2 - arithmetic mean of activities after lymphatic drainage

However, we must emphasize that in the case of wrong diet and long-term termination of lymphatic drainage, lymphedema is recurrent and associated pain and reduced quality of life.

\section{Conclusion}

The main goal of our study was reveal the influence of lymphatic drainage on the quality of life of patients with lymphedema on the base of identified facts. According to the quantitative research carried out in the form of a questionnaire, respondents were in all cases when the treatment of lymphedema using lymphatic drainage was receding.

Our research shows that lymphatic drainage techniques are an important therapeutic tool in the conservative treatment of lymphedema. The influence of lymphatic drainage techniques is very pronounced and, in particular, is characterized by its constant action. Thus, from the point of view of the application of lymphatic drainage techniques, the baseline condition prior to therapy is not significant, the application of the therapy decreases the rate of lymphedema and the associated subjective perception of the reduced quality of life, always substantially the same constant ratio.

\section{Acknowledgements}

This publication was created in the frame of the project ,Completion of the technical infrastructure for the development of science and research at Alexander Dubcek University of Trencin through Hyperbaric Oxygen
Therapy“, ITMS code 26210120019, based on the Operational Program Research and Development and funded from the European Social Fund.

\section{References}

1. SPANIK S, KNOTEK J, BOLJESIKOVA E (2003) Malignant breast tumors. In: KAUSITZ J, ALTANER C et al. Oncology. Sience Bratislava. sec. XXVI, 412-423.

2. ZATONSKI W, DIDKOWSKA J (2008) Closing the gap: Cancer in Central and Eastern Europe (CEE). Eur J Cancer. 44: 1425-1437.

3. KHEIRELSEID EH, BOGGS JM, CURRAN C et al. (2011) Younger age as aprognostic indicator in breast cancer: a cohort study. BMC Cancer 11: 383-389p.

4. CERNICKY M (2011) Treatment of lymphoedema and restriction of the movement of the upper limb. In: SLOBODNIKOVA $\mathrm{J}$ Early Diagnosis and Screening of Breast Carcinoma, Department of Radiology, ISBN: 978-80-970723-5-3.

5. RIBEIRO PEREIRA ACP, KOIFMAN RJ, BERGMANN A. (2017) Incidence and risk factors of lymphedema after breast cancer treatment: 10 years of follow-up. Breast. 36 : 67-73.

6. PUGH S, STUBBS C, BATCHELOR A (2017) Managing upper limb lymphedema with use of a combined arm sleeve compression garment. Br J Community Nurs.; 22 (Sup10): S38-S43.

7. WILSON A (2017) Living with lymphedema. Br J Community Nurs. 22 (Sup10): S68-S69. 
8. KOMACEKOVA D et al. (2006) Physical Therapy. Martin, Osveta. ISBN 80-8063230-8.

9. GOTHARD L, HAVILAND J, BRYSON P, LADEN G, GLOVER M, HARRISON S, WOODS M, COOK G, PECKITT C, PEARSON A, SOMAIAH N, STANTON A, MORTIMER P, YARNOLD J (2010) Randomised phase II trial of hyperbaric oxygen therapy in patients with chronic arm lymphedema after radiotherapy for cancer. Radiother Oncol. 97 (1): 101-107.

10. TEAS J, CUNNINGHAM JE, CONE L, JANSEN K, RAGHAVAN SK, NITCHEVA DK, XIE D, BUTLER WM (2004) Can hyperbaric oxygen therapy reduce breast cancer treatment-related lymphedema? A pilot study. J Womens Health (Larchmt). 13 (9): 1008-1018.

11. GOTHARD L, STANTONA, MACLAREN J, LAWRENCE D, HALL E, MORTIMER P, PARKIN E, PRITCHARD J, RISDALL J, SAWYER R, WOODS M, YARNOLD J. (2004) Non-randomised phase II trial of hyperbaric oxygen therapy in patients with chronic arm lymphedema and tissue fibrosis after radiotherapy for early breast cancer. Radiother Oncol. 70 (3): 217-224.

12. ZIGO R, KRAJCOVICOVA Z, MELUS V, RALAUSOVA E, SCHLENKEROVA D, PATLEVICOVA M, GRANACKOVA K, VECERA J (2017) Verification of the impact of hyperbaric oxygen therapy in the treatment of sudden sensorineural hearing loss. Otorhinolaryngology and phoniatry. 66 (1): 28-34, ISSN 1210-7867.

13. KRAJCOVICOVA Z, HOLLA M, MELUS V, KASLIKOVA K (2015) Molecular Aspects of Mechanisms of Effect of Hyperbaric Oxygen Therapy of Selected Diseases. Medical tops. 3 (4): 56-61.

14. JAIN KK (2009) Textbook of Hyperbaric Medicine. Hogrefe and Huber Publishers, Gottingen. 578p. ISBN 978-0-88937-361-7.

15. KRAJCOVICOVA Z, ZIGO R, MATISAKOVA I, MELUS V, GERLICHOVA K (2016) Evaluation and interpretation of preliminary results of audiometric tests in subjects with impaired hearing exposed in the conditions of hyperbaric oxygen therapy. University review. 10 (3): 2-6. 